\title{
Place, Pedagogy and Play
}

PARTICIPATION, DESIGN AND RESEARCH WITH CHILDREN

Edited by Matluba Khan, Simon Bell and Jenny Wood

First published 2021

ISBN: 978-0-367-08636-7 (hbk)

ISBN: 978-0-367-08637-4 (pbk)

ISBN: 978-0-429-02347-7 (ebk)

\section{2}

CHILDREN'S PERSPECTIVES

ON GREEN SPACE MANAGEMENT

IN SWEDEN AND DENMARK

Märit Jansson and Inger Lerstrup

(CC BY-NC-ND 4.0)

(2) $\begin{aligned} & \text { Routledge } \\ & \text { Taylor \& Francis Group } \\ & \text { LONDON AND NEW YORK }\end{aligned}$ 


\title{
CHILDRE N'S PERSPECTIVESONGREEN SPACE MANAGEMENTINSWEDEN AND D E N M A R K
}

\author{
Märit Jansson and Inger Lerstrup
}

\section{INTRODUCTION}

The work of green space managers - local authority department staff, external contractors, or caretakers employed by institutions or companies - can be expected to have a great effect on child-friendliness by affecting mainly physical, but also socio-environmental determinants. The Scandinavian countries have a history of being world-leading in work to improve the child-friendliness of environments, with much awareness of this issue during the early and mid-twentieth century. Children's levels of independent mobility are generally high, but diminishing, probably due to urban densification and increased car traffic (Björklid and Gummesson, 2013). The UN Convention on the Rights of the Child has been ratified and promoted, but less attention has been given to later international movements, and planning in Scandinavia has been criticised for not taking a child-friendly direction (Björklid and Nordström, 2007), with a focus on densification, urban character and new public management solutions.

Much of the literature on child-friendly environments focuses on participatory approaches to development of the physical environment (Alarasi et al., 2016; Cushing, 2016). Children's participation in planning can be highly valuable, but is not the only way to approach child-friendly environments, since these also depend on other practices, as well as on basic physical and social environmental factors. These can be developed both with and without children's direct participation. In this chapter, we examine the specific role of green space management in developing childfriendly environments, focusing on children's perspectives. We argue the importance of green space management to children, and suggest how managers can understand and strive towards child-friendliness in their approach to management of the urban environment. We argue that this work has huge potential, which is yet to be fully acknowledged and realised.

\section{ELEMENTS OF CHILD-FRIENDLINESS}

According to Gibson (1979), what humans directly perceive as opportunities in their surroundings are affordances, here defined as the meaningful action possibilities of the environment (Lerstrup and Konijnendijk van den Bosch, 2017). These are situated in time and space, and depend on many variables, such as the characteristics of the individual, where age, size, ability, former experiences and company exert an influence. Richness of affordances in local environments is an important factor in itself and can also support children's independent mobility, as interesting settings can encourage children to go outdoors, providing an "outward pull" (Chatterjee, 2005:19). For planners, designers and managers, the perceptions of affordances by various user groups and individual users should be of interest and might point to new and interesting ways to develop the environment.

Child-friendly environments can have various properties, but generally have some qualities in common, such as moderate building density (Broberg et al., 2013) and limited access for car traffic (Björklid and Gummesson, 2013; Carstensen, 2006). Horelli (2007:283) defines environmental child-friendliness as: "settings and environmental structures that provide support to individual children and groups who take an interest in children's issues so that children can construct and implement their goals or projects". In other words, such environments include elements 
and structures providing the two components rich affordances and support for independent mobility (Kyttä, 2004; Jansson et al., 2016). They allow children to perform meaningful actions, such as constructing, affecting and creating their own places, and they often include green elements providing rich sensuous experiences, loose parts and change (Chawla, 2015; Jansson, 2015; Lerstrup, 2016; Rasmussen, 2004).

Children are often among the most frequent green space users near their homes (Florgård and Forsberg, 2006). Green spaces are important for child-friendliness (Jansson et al., 2016; Kyttä, 2004; Riggio, 2002) and several positive aspects of children's contact with such spaces have been found (Chawla, 2015). For example, they support children's physical activity, which for 11-13 year-olds can depend on the amount of space with trees and shrubs near their homes (Janssen and Rosu, 2015). Furthermore, spacious preschool yards with much vegetation and a mix of spaces that are open and spaces with natural and fabricated content are associated with children that have healthier body mass, sleep better and are only exposed to balanced amounts of solar radiation, as compared with children attending schools with other kinds of yards (Boldemann et al., 2011; Söderström et al., 2013). Thus, the access, amount and quality of green spaces are important aspects, which set a focus on the contribution of landscape practices.

The development of environments through landscape architecture is commonly divided into three phases: planning, design and management (van den Brink et al., 2016). Planning and design mainly concern the development of new elements and structures, while management deals with maintaining and developing existing elements and structures over time. These three phases can all affect environmental child-friendliness (Horelli, 2007), but management is particularly underexplored in this regard, despite being about providing qualities for people or users. In the context of green spaces and landscapes, management has been defined as "the activities performed by a management organization to maintain and develop existing urban green space for users" (Jansson and Lindgren, 2012:142) or as "maintaining and enhancing [a place and] its quality to maximize the benefits for users" (Dempsey et al., 2014:24). Green space managers are a range of professionals who work with management of public open spaces, but also institutions, cemeteries and housing areas that are both semi-public and private. Three management levels are generally distinguished, most clearly in local authorities: policy (politicians), tactical (civil servants) and operational (park workers) (Jansson and Lindgren, 2012; Randrup and Persson, 2009). On the policy and tactical levels, management is clearly more than operational upkeep and maintenance, and is even intertwined with planning (Jansson and Lindgren, 2012). Management processes could include users on local, informal, handson and 'everyday' levels, potentially facilitating inclusion of children's perspectives (Clark and Percy-Smith, 2006; Jansson, 2015). This requires approaches which give insights into children's perspectives in a way that is relevant for management.

A few previous studies have examined the child-friendliness of urban green space management. In school grounds, Malone and Tranter (2003) found management activities to be of value for promoting children's learning and play, while Jansson, Mårtensson and Gunnarsson (2018) found that children's participation in the management phase was positive for their attitude to school ground development. In other green spaces, Bell et al.,(2003) concluded that managers lack sufficient insight into the uses and perspectives of children and young people. Moreover, Roe (2006) reported that children did not feel that the management of their local environments was adapted to them and their preferences. Jansson et al., (2016) found that children can take an interest in green space management and prefer variation in management levels. In the empirical studies we detail in this chapter, we investigated how green space management and its results are actually perceived by children in Denmark and Sweden, and how management in various forms can affect and contribute to the child-friendliness of urban environments.

\section{STUDYING GREEN SPACES WITH CHILDREN AS USERS}

We collected data for the studies based on the concept of children's perspectives as a methodological driver for child-friendliness and child-centred methods. The concept, introduced in the 1990s (Tiller, 1991), has gained 
attention in the literature during recent years, including in research on children's local environments, where childcentred methodologies and children's own views are at the core (Bourke, 2014; Cele, 2005; Elsley, 2004; Jansson et al., 2016; Kylin and Lieberg, 2001; Lerstrup and Refshauge, 2016; Prellwitz and Skär, 2007; Rasmussen, 2004; Roe, 2006; Simkins and Thwaites, 2008). The approach aims at understanding children as individuals, but their perspectives also depend on a variety of factors such as age group. In our studies, we invited children in school year 4, aged 10-11, to participate through collaboration with local municipal schools. Children in this age group have previously been included in similar studies (Bourke, 2014; Cele, 2005; Kylin and Lieberg, 2001), since they generally have some independent mobility, are interested in their local environments and are able to communicate their perspectives, while still being engaged in play (Jansson et al., 2016).

Case study methodology is based on an interest in exploring context-bound cases through various methods (Stake, 1995) and is therefore valuable for studying uses related to environments. We used multiple cases in order to broaden our view and permit comparisons of children's perspectives, as previously done by e.g. Carstensen (2006) and Haikkola et al., (2007). The case study included four urban areas with similar, rather high, socio-economic status, but with variations in building density and the amount and character of green space available for users. These were two case areas in southern Sweden and two in eastern Denmark, with one urban village, representing smaller built-up areas with an urban lifestyle, and one city district, representing part of a larger and denser city, in each country. Among the cases, the Swedish urban village had the lowest density, the most green space and the most limited car traffic, while the Danish city district had the highest density, the least green spaces and much car traffic. We selected the cases to allow for comparison and generalisation of the results (Flyvbjerg, 2006).

\section{USING CHILD-CENTRED METHODS}

In our field studies, we arranged walking interviews with five to six groups of three children, with a total of 15-18 participating local children in each case area. We thus aimed to combine our former experiences of semi-structured interviews with observations of places and children's activities on-site. Methods that are child-centred and conducted outdoors (Cele, 2005) or in groups (Hill, 2006) have often been found to be valuable. These can be combined in socalled child-led walks where children take the lead in showing and describing their environments, supplemented by semi-structured interviews on the go. Child-led walks are increasingly being used and recommended for gathering data on children's perspectives on their environments (Cele, 2005; Jansson et al., 2016; Kylin and Lieberg, 2001; Loebach and Gilliland, 2010; Moore, 1986).

In collaboration with local schools, we obtained written consent from parents for their children's participation in the study. The teachers formed the children into groups, each containing children from the same class who knew each other well and lived close to each other. Some groups contained only boys, some only girls and some both boys and girls. Throughout the study, the children were informed about the aim to learn from them and the voluntary nature of their participation.

Before the child-led walks, we introduced the children to the research topic either during a short preparatory indoor interview or during a drawing and writing task, both with the focus on local outdoor environments. The task was given some structure by asking the children to draw or describe local outdoor areas and by posing four questions: What do you do there? What do you think of the way it is being cared for and organised? What do you think is good there? What do you think is bad there?

The walks lasted 1.5-2 hours each and were held when the weather was comfortable, during May in the Swedish urban village and in September-October in the other cases. On starting the walks, we instructed the children in each group jointly to decide which local places to visit. While walking, we had group conversations 
about places, activities, preferences and suggestions, supported by semi-structured questions about the environment and their use of it, places suitable or unsuitable for them, the arrangement of the outdoor environment and the management work there, what was allowed and the need for improvements. We observed how the children acted and interacted with the environment during the walks. On the go, we made digital audiorecordings and took some photographs. Immediately after each walk, we wrote down what we could recall, including observations of actions, surprising observations and reflections. After finishing each case study, we summarised the general impressions of important activities, environmental elements and general advantages and problems of the area.

When all the walks were complete, we listened to the audio-recorded interviews, transcribed sequences illuminating the research questions, went through the notes and looked at the photos taken to support memories of places and activities. We also reviewed the drawings and written statements made by the children to get an idea about how they related to their local outdoor environments, the management of outdoor areas and the affordances in the case areas for this age group. Through the content in these various data types, we formed themes related to our aim and condensed the results to facilitate comparisons between the case areas.

\section{CHILD-FRIENDLY ENVIRONMENTS}

In the following paragraphs, we describe our findings about 10-11-year-old children's use of open spaces, characteristics of child-friendly environments and the role of green space management. In all four cases, children expressed that they were connected to and liked their local environment. Many findings were general for the four sites, while some differed between them (Table 12.1). After analysing our material, the findings could be structured into four themes on how green space management can affect child-friendliness: development, maintenance, urban planning and approach to children (Figure 12.1). Within each theme, three aspects are distinguished, varying in importance from case to case.

TABLE 12.1 Differences in types of settings shown, relation to green space management and children's independent mobility in the four case areas

\begin{tabular}{ccc} 
& Sweden & Denmark \\
Urban & Playgrounds, variety of green spaces, ponds, & Schoolyards, sport facilities, playgrounds, private \\
village & unmanaged places (overgrown gardens and & gardens, low-managed places (beach, forest, hedges, \\
& railway), streets, paved paths. & grass slopes), paved paths. \\
& Some interest in green space management. & Low interest in green space management. No feeling of \\
& Weak feeling of influence on management. & influence on management. \\
& Overall much independent mobility. & Variation in independent mobility. Boys generally less \\
& & restricted. \\
\hline district & Varied green spaces, playgrounds, low-managed & Schoolyards, private courtyards, private gardens, \\
& places (river banks, woodlands), pavements, & playgrounds, squares, parks, few low-managed places. \\
& paved paths. & \\
& Low interest in green space management. Weak & Low interest in green space management. No feeling of \\
& feeling of influence on management. & influence on management. \\
& Much independent mobility, a few exceptions & Overall low independent mobility with variation between \\
& among both boys and girls. & children. Boys generally less restricted.
\end{tabular}




\section{A. DEVELOPMENT OF SETTINGS}

Development of settings is one of the main tasks of green space managers. In this aspect, we identified three aspects of increasing child-friendliness for the age group investigated: to develop a variety of places for children's actions, to manage for change and to add sensory plants (Figure 12.1).

\section{Develop variety for action}

Children in all case areas used the environment for actions: to meet, play, move, construct, explore and observe, in green spaces as well as in shops and public areas. Playgrounds were used as places to meet and for activities with peers and siblings, and meeting a cat or a dog was interesting for most children. Apart from socialising, several enjoyed moving around on play equipment: climbing, jumping on trampolines, swinging, swaying and spinning when possible. Open spaces were used for group games such as tag and all kinds of moving, such as cycling, skating, running, etc., and vegetated areas for group games such as hide and seek, role play, climbing, balancing and jumping.

Generally, children valued variation in content and management level. They enjoyed all kinds of landscapes and wanted open spaces as well as enclosures, evenly paved ground as well as grassy slopes, short grass for ball games as well as tall grass for hiding and supporting animal life, cultivated plants such as fruit trees and berries as well as flowers and wild herbs. Children were fond of play equipment as well as natural elements such as vegetation and boulders. These preferences were evident both in their drawings, which often contained elements such as trees, grass, water and play equipment, and during the walks, where they used both green and built elements in multiple ways. A number of children wished for more smooth surfaces for skating and cycling, more challenging play equipment such as climbing structures and several large trampolines, and more interesting areas to explore with loose objects to arrange and thus leave their mark.

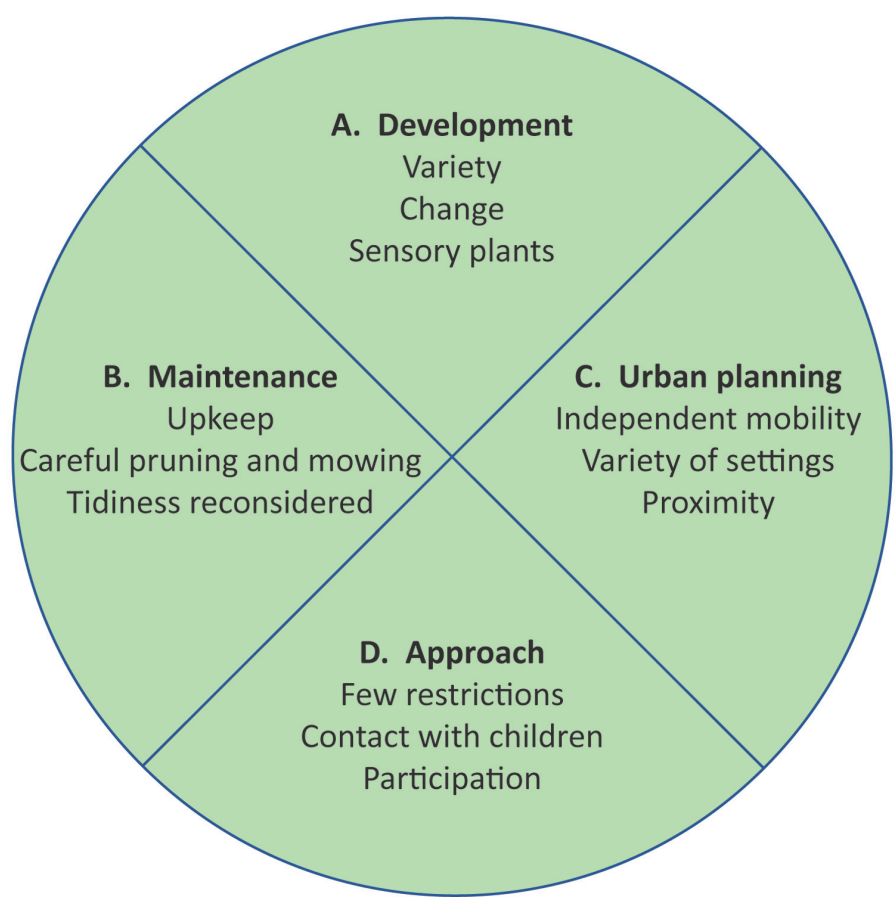

FIGURE 12.1 Four themes describing ways (A-D) for managers to affect the child-friendliness of outdoor environments Source: the authors 


\section{Manage for change}

The wish to construct, explore, observe and talk underlined children's curiosity and appetite for something new to happen, something new to experience, explore and reflect on. This is why it is important to manage for change, either by replacing elements and structures regularly or by including much vegetation, since vegetation changes naturally through the seasons and attracts wildlife.

Vegetated areas were used as resources for loose objects such as leaves, fruit, flowers and sticks for construction. Vegetated areas, un-managed areas and settings with water were used for exploration. Overall, children highly enjoyed water that they found in ponds, fountains, streams or at the beach, particularly when they had loose objects such as stones or flowers to throw in. A specific feature of the Swedish city district was the water present in streams and canals, which fascinated the children. A specific feature used by those who lived in the urban village in Denmark was strolling by the sea, finding treasures and bathing. In all study areas, observing peers in action or adult activities such as house and road construction, walking a dog or skinning a fish was interesting. Observing was often accompanied by talking and reflecting. A specific feature of the city district in Denmark mentioned as attractive was events arranged by the local chamber of commerce.

\section{Add sensory plants}

The curiosity of children was not restricted to viewing and listening, but also included senses of touch, smell and taste. They showed an interest in how to use plant material in their local environments. This was most clearly shown in the focus on growing and particularly in edible plants. During the walks, several tasted and chewed things such as leaves, fruits etc. Many children were aware of edible plants in their surroundings. They pointed out fruit trees, berry bushes, herbs, even shops giving out sweets or buns for free or very cheap. Some children participated in cultivating flowers and vegetables in their gardens and courtyards (Figure 12.2). Others, mainly in the Swedish case areas, talked a lot about fruit trees and picking fruits and berries from trees, which were seen as beautiful and useful for both play and food.

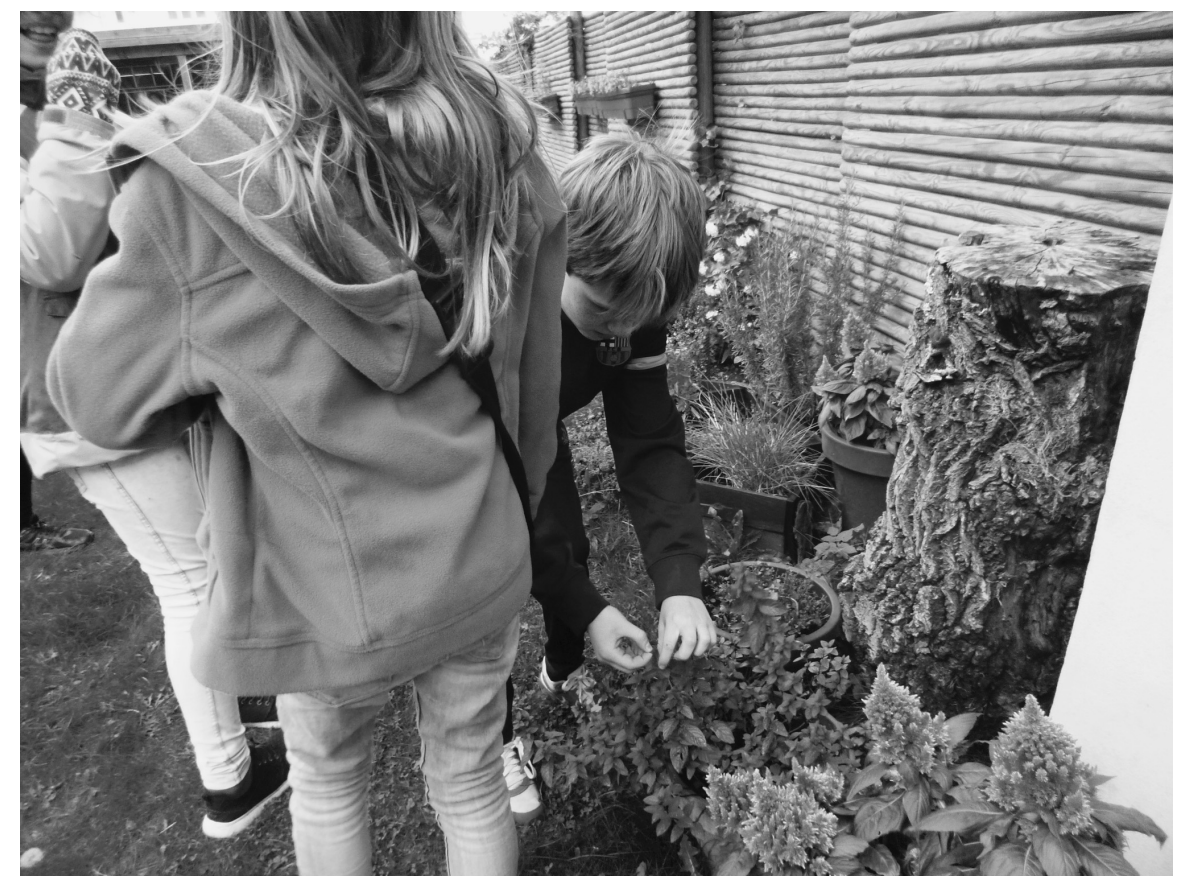

FIGURE 12.2 Tasting and eating fruit, berries and herbs was an attractive activity, particularly in the Swedish and Danish city districts Source: Inger Lerstrup 


\section{B. MAINTENANCE OF SETTINGS}

Another main task for green space managers is maintenance and upkeep on the operational level. Connected to maintenance, we found three aspects of importance for the children: upkeep of play structures and other facilities, pruning and cutting of vegetation and the level of tidiness (see Figure 12.1, p. 198).

\section{Take care of play structures}

Common complaints among the children were that the upkeep of play equipment was poor. Swings, climbing frames, football goals and basketball hoops were not taken care of, repaired or painted, something that the children often pointed out during the walks. Between the lines, children expressed the feeling that their age group was not considered as important as younger children or adults. Settings that they preferred were often not well-kept or were even removed. Children complained about old play equipment being replaced with something less interesting and intended for smaller children, or not being replaced at all.

\section{Prune and cut vegetation sensitively}

Some complaints concerned the lack of consideration of children in management, particularly in residential courtyards, but also in some public areas. Some of this referred to 'insensitive maintenance' of vegetation, e.g. that shrubs used for hiding were pruned back too hard (Figure 12.3), grass was cut too short and interesting vegetation structures taken down. In several cases, children reported felling of beloved trees used for climbing, swinging or sitting in the shade reflecting and listening to the birds. In many places there was clearly a lack of both knowledge and child perspective in the vegetation maintenance. It appeared more focused on practical aspects and a will to demonstrate a high maintenance level than on the vegetation quality or usefulness for children. On the other hand, we observed that not all children interacted with vegetation even when this was possible.

\section{Reconsider tidiness}

Children expressed complexity in their views on tidiness and aesthetics, with a clear focus on possibilities for action. They admired beautifully coloured flowers and picked up the colourful petals from the ground and all kinds

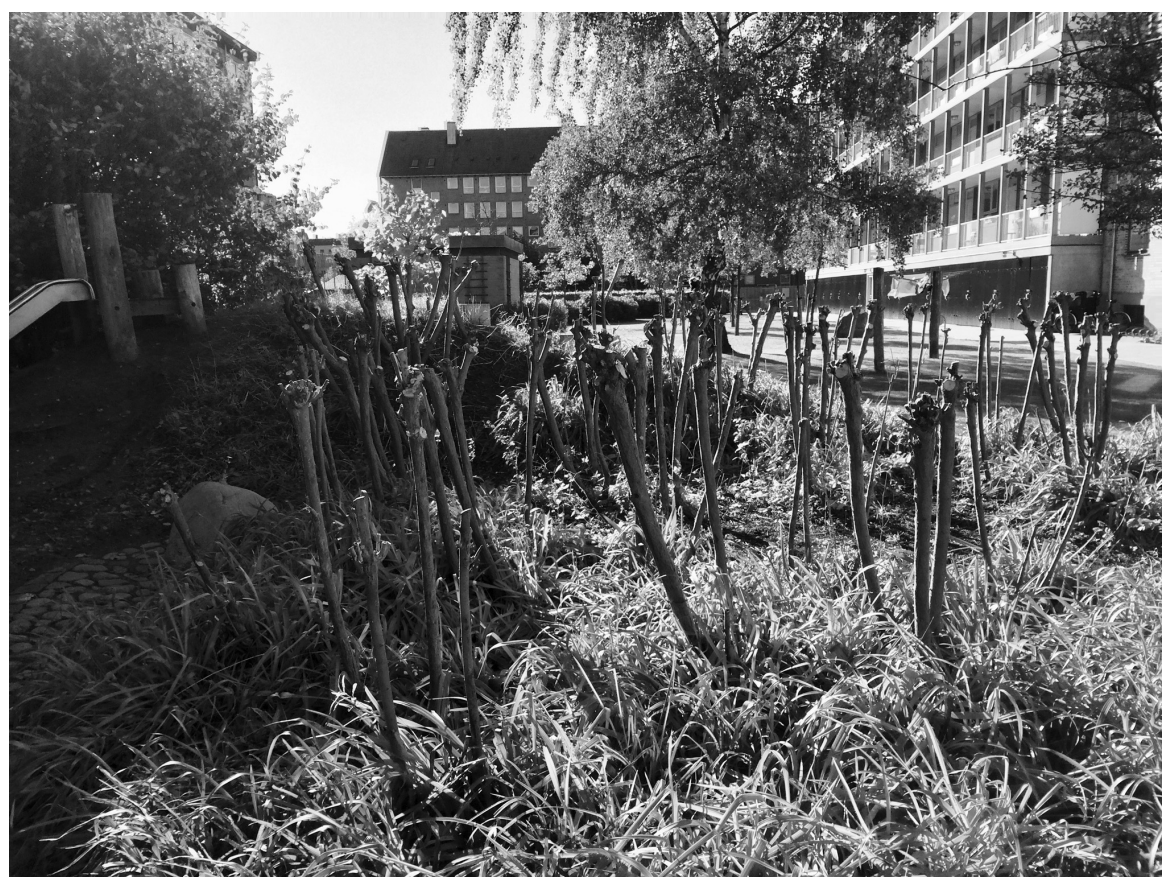

FIGURE 12.3 Danish city district. Before maintenance, this had been an attractive place for playing hide and seek Source: Inger Lerstrup 
of sticks, stones, shells, fruits and leaves. They also enjoyed bunches of fallen leaves on the streets, soon to be removed by maintenance staff. Overall, the children showed interest in the physical environment and its loose parts and in any variations, changes or irregularities there, including broken items and litter. In the Swedish city district, children complained about lack of pavement in the streets after ground work, but at the same time played with the road gravel there.

Litter was not always considered a problem and some children in the Swedish urban village even thought it was fun to find litter items, while dumped waste, dog waste and cigarette butts, waste associated with adults, were generally disliked. The opinions on graffiti varied in the Danish case areas; many children found it amusing, but some made a distinction between 'ugly graffiti' such as tags and 'nice graffiti' with colourful images. One group expressed a wish for a wall for graffiti, so that they could contribute without breaking the rules.

\section{URBAN PLANNING}

Physical planning has a huge influence on children's action possibilities in environments. Planning practice is largely conducted by actors other than green space managers, but it is related to management both directly and indirectly. It sets the frames for children's possibilities and for the work of managers, but can also be dynamically related to management. In our case studies, we found three main aspects of planning that relate to management and are important for children: support for children's independent mobility, provision of various settings and proximity (see Figure 12.1, p. 197).

\section{Support chilldren's independent mobility}

The qualities of green spaces can support children in experiencing and moving independently in their local area. The range of independent mobility varied widely between individual children in the case areas (see Table 12.1, p. 197), as revealed both in the drawings and texts and during the walks. Some did not move on their own at all and were accompanied to school and home by their parents. At the other end of the spectrum, some children were allowed to go wherever they liked on their own. Some children used the outdoors much and moved between various spaces. Others mainly reported using the outdoor environment for transport between home and school, otherwise playing computer games, watching videos and following Youtubers, or attending organised after-school activities. A few children in the Danish city district did not relate to any outdoor places and some could only draw outdoor places from locations associated with holidays, such as their summer cottage.

An important finding is that independent mobility was not only individual, but also varied much between the four case areas. The children in the Swedish case areas, particularly in the urban village, had much independent mobility. Within the village, the children were generally not restricted and freely used the path system and the streets where car traffic was low. Some even moved outside the village, going jogging or taking the train to the nearby city. In the Swedish city district, most children moved freely on foot or bike at least to school and in large areas around their homes. A clear exception was a boy who lived slightly outside the urban area and whose house had a road on one side and farmland on the other. He was not allowed outside his garden on his own and found this very limiting. In the Danish case areas, there were some children with much independent mobility, for instance some children in the urban village could go to the beach and even paddle if they liked. The children in the dense Danish city district demonstrated the most restricted independent mobility of all case areas, with a few children hardly having any places to show and being unable to find their way to known places.

Independent mobility is affected by physical environments, but relates to social factors. The areas used by the children had mostly been introduced to them by parents, older siblings or peers, but also by teachers during field trips arranged by the school. Mobility was restricted in dense areas with much car traffic, but also in relation to, for example, what parents allowed. This appeared to affect cycling more than walking. Very few children, and only boys, were allowed to cycle on their own in the Danish city district because of the traffic. On the other hand, scooters 

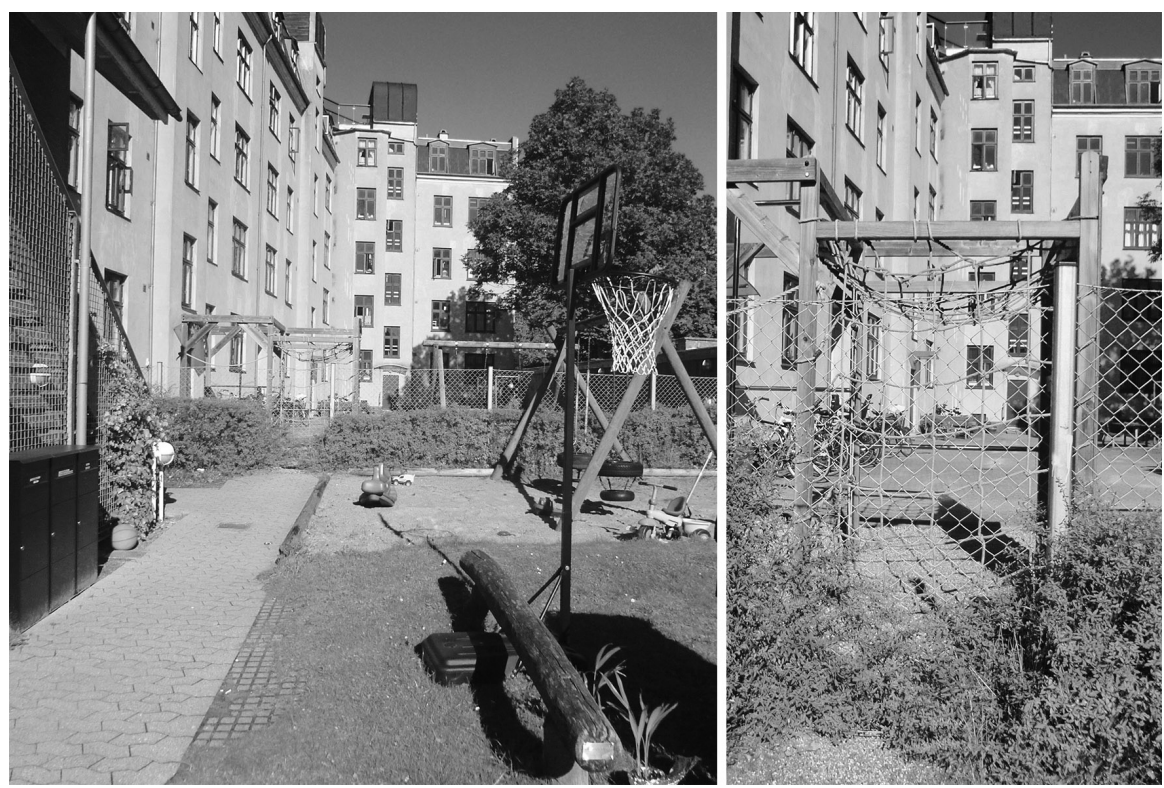

FIGURE 12.4 A Danish courtyard in the city district, where there was formerly an opening in the fence giving children direct access to the neighbouring courtyard Source: Inger Lerstrup

(kick bikes) were sometimes used for trips there, unlike in the other case areas. Most girls there appeared to be allowed less independent mobility than most boys, having to follow stricter routes from school to home and call their parents to ask for permission if they were invited to a friend's house, whereas many boys could wander as they pleased or just leave a message when visiting a friend.

The children wanted a large number of places to access and the possibility to move in between them, with few hindering fences and borders. Many said that they enjoyed the child-led walks and seeing the places used by other children in the group, sometimes discovering shared affection for a place, at other times being introduced to new places. Some children asked to be invited to revisit peers' private gardens or yards. This underlines the importance of friends and the places to which they provide access. The borders to use and mobility were often physical, such as car traffic and fencing. In some places, residential yards had been renovated and merged to increase the access for residents. In another case, the children had formerly enjoyed access to the next residential yard through a hole in the fence, but then the fence had been replaced (Figure 12.4), much to the displeasure of a child who had a friend in the other yard.

\section{Provide various settings}

Both planning and development can contribute to a variety of settings. The sites used by children varied naturally with the character of the case areas and the possibilities afforded by elements and structures there. These variations were prominent and reflected in the sites that the children knew and used (see Table 12.1, p. 197). The variety of settings available clearly had an impact on children's use, and thereby also on their mobility.

In the Swedish urban village, the children showed us a multitude of places. These included playgrounds, among which they had a few favourites that suited their preferences for socialising around large swings or playing in green surroundings. They also used various green spaces for ball games, exploring and moving around. Ponds and other water bodies and a few abandoned and overgrown lots were objects of much interest. Children in the Swedish city district also reported large variation in the outdoor areas they used, including playgrounds, woodlands and parks of various types and some areas clearly not intended for their use. For example, a group of girls showed a steep track through a broken fence to a beautiful view of a pond and a golf course. The Danish urban village had a network of 
paved paths, smaller green patches and some less intensively managed lots, but the children quite often showed their private gardens or courtyards and less often other areas. The village was surrounded by arable land, forest and the sea, which attracted some interest. The Danish city district was adjacent to quite a large park and included several small parks and a few playgrounds, but there were almost no vacant lots and un-managed places. Apart from certain areas in the park, only one unmanaged place was presented by the children, a vegetated railway embankment accessible through a hole in the fence. The children instead used many private courtyards.

\section{Provide proximity to settings}

Areas close to the children's homes were of the greatest importance for their use. Management of settings to be inviting, varied and different is also therefore particularly valuable to provide proximity. In the Swedish urban village, most children knew more or less the entire urban area, but they were much more familiar with spaces close to home. Children in the Swedish city district lived spread over a large area and mostly at some distance from the school. They rarely related to the forested areas close to their school, but frequently to their nearest neighbourhoods. In the Danish urban village district, children living in one neighbourhood mainly used the school facilities and their private gardens, but in another neighbourhood the courtyards and playgrounds were of higher importance. Likewise, in the Danish city district, some children mainly used the school facilities and private courtyards, while those living in another part of the district used a large public park and those in yet another part used squares and a shopping centre.

\section{APPROACHTO CHILDREN}

The affordances for children in the case areas were influenced by the mindset of the managers and their attitudes and approaches to children as actors and users. This included restrictions of children's activities, managers' contact with children, or lack thereof, and children's participation in management, or lack thereof (see Figure 12.1, p. 197).

\section{Minimise restrictions}

The children were heavily affected by local restrictions, which were more prominent in residential courtyards and thereby more influential for children in the Danish city district than in the other case areas. Certain activities were also prohibited, for instance climbing on the roof of sheds and playhouses, swinging on the gates, picking flowers, throwing apples, picking up sticks, climbing in trees, playing in shrubs or making fires. These bans were most often enforced by courtyard caretakers or green space managers, but parents of smaller children also scolded other children and restricted their actions in playgrounds. Many children also pointed out that visiting certain places was not permitted. The railway embankment was fenced off, some institutional playgrounds were not open for all children or only open within certain hours, gardens and courtyards were closed to non-residents and so on. These observations from the children chime with Wood's chapter in this volume, where even the places intended for children contain restrictions that reduce their enjoyment.

\section{Make contact with children}

Children's uses of their local outdoor environments and their views on green space management varied, but they seldom perceived management as something they could affect or even give their opinion on. The drawings and texts generally expressed little about green space management. During walks in all case areas except the Swedish urban village, we met with or saw green space managers in action. We observed that some children followed their work with interest, but others did not seem to see the managers at all and referred to them as "somebody from the local authority" when asked.

In the Swedish urban village, some children had talked to local green space managers, had some ideas about their work and said that they liked to see people take care of the environment. Some were upset about major changes to the environment, but understood that this was due to decision-makers rather than to maintenance staff. They 


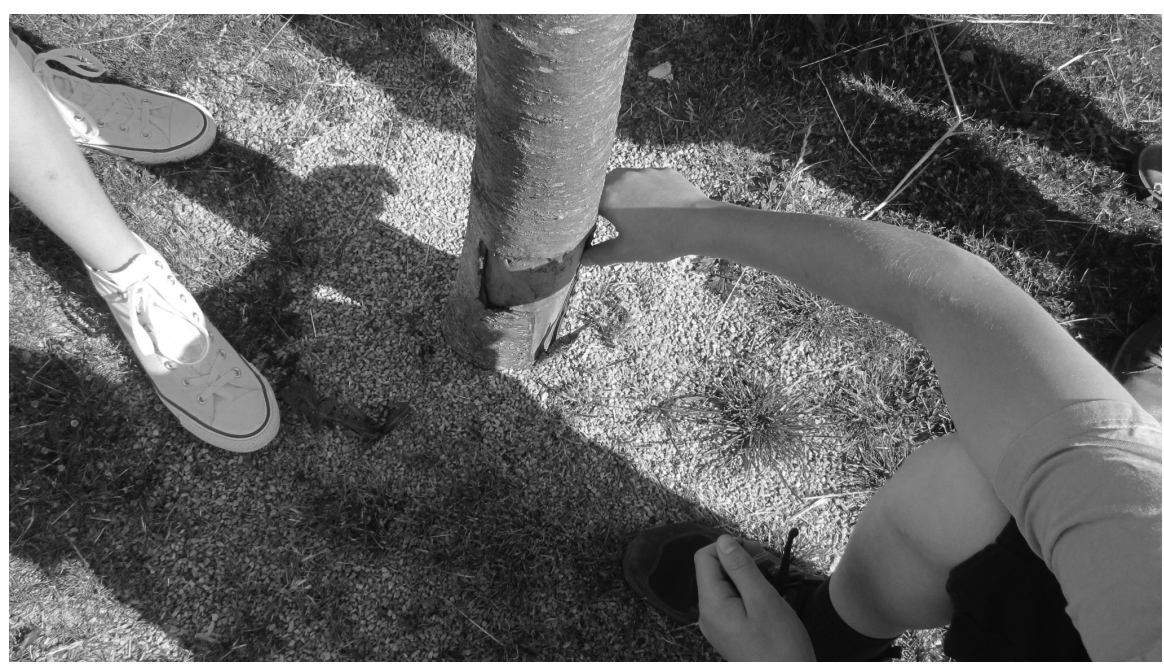

FIGURE 12.5 Swedish urban village. Children showed engagement in the quality and care of the green spaces, looking at a damaged tree Source: Märit Jansson

also showed that they cared for the environment and the quality of green space (Figure 12.5). In the other areas, children did not consider it possible to talk to managers they met during the walk. When passing a playground reconstruction in a school yard in the Danish city district, children were interested, but not informed about what was being done. When passing a playground under reconstruction in the Swedish city district, the children only looked at it until the researcher encouraged them to talk to the staff. However, a few children had been in contact with managers, for example when a large grass surface was mown by horse-drawn machinery, which the children liked. Only a couple of times did we observe a dialogue between children and managers, but it was not concerning management or maintenance.

\section{Consider dialogue and participation}

In the Swedish city district and the Danish case areas, very few children had any notion of their own possible influence over green space management. In a few groups, they knew the caretakers, but it did not strike them that they could express their opinions or that they might be of interest to the staff. On the contrary, many children mentioned that trees were felled, play equipment removed, bushes and grass cut and activities forbidden, as if these were unalterable aspects of life. They had no idea whom they could inform about their wishes and thought that neither they nor their parents could have any influence with local caretakers, even in their own residential courtyards. We did not hear about direct participation by children at any level of the management process.

\section{METHODOLOGICAL REFLECTIONS}

The methods we used gave new insights into the relationship between children and the urban environment, adding to findings from previous studies. The drawings and written statements made in the classrooms provided a basis for getting an overall view of the children's use of their outdoor surroundings, but this method was more challenging in analysis and interpretation and did not reveal as rich information as when the children were outdoors.

Walking and talking with children on child-led walks gave the opportunity not only to ask questions and listen to answers, but actually to see the sites in use and to observe how children related to them. Being present at the sites, the children revealed their detailed place knowledge and place attachment. The observations made during the walks, for instance how fallen leaves were kicked, flower petals picked and admired and fruit tasted by the children, were of course season-bound, but the children also mentioned activities performed at the sites in other seasons. 
The main research method used, child-led walks with open and semi-structured interviews, proved to be especially suitable for studying how children's perspectives on environments and management differ from those of adults. Actually, it was a challenge to address children directly on green space management, as they knew little about the subject. The combined method delivered much information about the children's attitudes to green space management, but most of it was indirectly shown or described.

The small groups of three children who lived quite close to each other, knew each other and were eager to go out with us were very informative about each area. This selection might be seen as a weakness of the study, since the children might not be representative for the age group, but it was a deliberate choice to gather children's placebased knowledge and encourage children's interaction in the study.

Our child-led walks showed that this method may be time consuming, but not very complicated. For local managers, it can be adjusted according to time available and, as we show, even a small attempt to make contact and listen to this user group can yield useful information. Children can show and describe their local environments very well, how they use them and can express their wishes, if adults in different roles take an interest in developing collaborative and inclusive approaches to children. An issue for the future is how green space managers can involve children practically in their work. We need to develop methods, based on child-led walks and other child-friendly approaches, whereby managers can be informed by children's views and experiences.

\section{UNDERSTANDING CHILD-FRIENDLY GREEN SPACE MANAGEMENT}

Overall, the results from our empirical studies show the importance of green space management for the childfriendliness of environments. The study confirms that children's perception of affordances and perspectives on environments and management differ from those of adults (Francis, 1988; Bell et al., 2003; Kylin, 2003). At the same time, the study shows a surprising lack of constructive contact between children and green space managers. Children's views on and interest in green space management varied, but in any case, they did not know where to express their opinions about management. This is surprising, since the UN Convention on the Rights of the Child, stating children's rights to express themselves in matters that affect them, has long been promoted in both Sweden and Denmark.

It is not easy to isolate the role of green space management, while other aspects of the physical and social environment and children's individual preferences and personalities also affect how they use their local environments. Children's individual uses are also affected by social and individual factors including parents, siblings, friends, teachers and their state of mind. However, we argue that green space management can generally contribute to child-friendliness by offering varied, rich, allowing and changing environments, sensory plants included. These attractive outdoor environments should be close to children's dwellings and institutions and safely accessible for children.

Participation by children can occur on many levels, from more or less decisive participation in decision-making processes to direct inclusion in operational maintenance. If green space managers want to manage with children in mind, they would benefit from knowledge on children's perspectives as green space users. This knowledge may be entirely theoretical, or may be influenced by observations of children or by wear and tear in the setting. More direct contact and dialogue between children and managers can be a way of bridging the gap between the perspectives of children and managers and of creating understanding for use on a local level. By involving local children in management and practical green space maintenance, green space managers have the opportunity to understand and make use of local children's place-based experiences, knowledge and visions. If green space managers are more flexible and allow children to interact, for instance providing some extra tools in small sizes, informative chats may take place and good ideas for child-friendly management may turn up. This kind of informal work and chat might fit many children well (Jansson, 2015), even better than more formal participation in indoor meetings and workshops, 
such as is sometimes done in planning. Drawing on more hands-on participatory methods in everyday spaces, as proposed by Clark and Percy-Smith (2006), green space managers can meet the needs of the different individuals and groups within children's communities.

All else being equal, it must be more manageable to involve children in areas where the staffing is good and the green space managers themselves know each setting well and have time to observe the use, wear and tear. The current new public management trends with use of external contractors make it less easy to observe and relate to children, unless the task 'involving children' becomes a goal in future contracts. However, our results show that long-term involved managers of more private housing areas might also fail to include children's perspectives. With the current changes towards more multifunctionality of green spaces and inclusion of several perspectives, comes a shift into a more complex task, which most green space managers have not been trained to handle (Molin and van den Bosch, 2014).

In the future we would like to learn more about child-friendly green space management in other parts of the world as well as about the views, opinions, working situations and tasks of green space managers relative to children as users and identify potential areas of conflict.

\section{CONCLUSIONS}

Environmental child-friendliness has several dimensions and is affected by individual, social and physical environmental factors. Although it varies from child to child, the local environment, including structures, elements and social environmental aspects, has a large impact.

While focus has been put on trying to include children and their perspectives in planning and design, management appears a neglected and particularly promising arena for this. In our studies, we learned that child-friendly environments for children aged 10-11 can be greatly supported by green space management approaches and we specifically identified the following management-related characteristics (see Figure 12:1, p. 198): presence of a number of varied sites, attractive places for a wide range of actions, support for change, incorporation of sensory plants, upkeep of structures, thoughtful pruning and cutting of vegetation and a reflected attitude to tidiness. Childfriendliness is also influenced by attempts to increase the possibilities for children's independent mobility and proximity of various settings. Children benefit from as few restrictions in their use of local environments as possible, and managers in various roles and levels may gain new insights into the challenges and possibilities for development of local open spaces through acquaintance with local children. This leads to the obvious conclusion that practical participation by children and their involvement in decision-making as well as in operational management can facilitate constructive communication and increase the child-friendliness of environments. While children's participation on city planning level can still be of importance, it is within management that children can clearly incorporate their local knowledge and engagement.

Child-friendliness is a complex matter involving many stakeholders, such as urban planners, green space managers, private landlords, teachers and parents. Among these, green space managers at different organisational levels might have a larger role to play than realised previously. Our data shows that, on the one hand, children are highly dependent on the management of their local environment, as their relation to place is directly affected by green space management, such as the availability of space, trees, water, playground equipment and loose items. On the other hand, children rarely see the work of managers as related to them or within their influence.

We consider children's perspectives to be a rich resource for green space managers and an important aspect of environmental child-friendliness. If the political and practical will to prioritise children is present, knowledge about children's experiences may lead to more child-friendly urban environments. In this chapter, we showed that childled walks in children's everyday contexts constitute a promising method to gain information about children's use 
and knowledge of their immediate surroundings, and we suggest dialogue and children's participation in operational management as a promising way to get ideas for increasingly child-friendly management of urban green spaces.

\section{ACKNOWLEDGEMENT}

This chapter is based on research project 225-2014-1552 funded by the Swedish Research Council for Environment, Agricultural Sciences and Spatial Planning, FORMAS.

\section{REFERENCES}

Alarasi, H., Martinez, J. and Amer, S. (2016) 'Children's perception of their city centre: A qualitative GIS methodological investigation in a Dutch city', Children's Geographies 14, 4: 437-452.

Bell, S., Thompson, C. W. and Travlou, P. (2003) 'Contested views of freedom and control: Children, teenagers and urban fringe woodlands in Central Scotland', Urban Forestry and Urban Greening 2, 2: 87-100.

Björklid, P. and Gummesson, M. (2013) Children's Independent Mobility in Sweden. Stockholm: Trafikverket.

Björklid, P. and Nordström, M. (2007) 'Environmental child-friendliness: Collaboration and future research', Children, Youth and Environments 17, 4: 388-401.

Boldemann, C., Dal, H., Mårtensson, F., Cosco, N., Moore, R., Bieber, B., Blennow, M., Pagels, P., Raustorp, A. and Wester, U. (2011) 'Preschool outdoor play environment may combine promotion of children's physical activity and sun protection: Further evidence from Southern Sweden and North Carolina', Science and Sports 26, 2: 72-82.

Bourke, B. (2014) 'Positionality: Reflecting on the research process', The Qualitative Report 19, 33: 1-9.

Broberg, A., Kyttä, M. and Fagerholm, N. (2013) 'Child-friendly urban structures: Bullerby revisited', Journal of Environmental Psychology 35: 110-120.

Carstensen, T. A. (2006) 'Byrum og ruter: På tur med børn i fire danske kvarterer', in K. Rasmussen (ed.) Børns Steder: Om Børns Egne Steder Og Voksnes Steder Til Børn. Billesøe og Baltzer.

Cele, S. (2005) Communicating Place: Methods for Understanding Children's Experience of the Physical Environment. PhD Thesis, Stockholm University.

Chatterjee, S. (2005) 'Children's friendship with place: A conceptual inquiry', Children, Youth and Environments 15, 1: 1-26.

Chawla, L. (2015) 'Benefits of nature contact for children', Journal of Planning Literature 30, 4: 433-452.

Clark, A., and Percy-Smith, B. (2006) 'Beyond consultation: Participatory practices in everyday spaces', Children, Youth and Environments 16, 2: 1-9.

Cushing, D. F. (2016) 'Youth master plans as potential roadmaps to creating child- and youth-friendly cities', Planning Practice and Research 31, 2: 154-173.

Dempsey, N., Smith, H., and Burton, M. (2014) Place-Keeping: Open Space Management in Practice. Abingdon: Routledge.

Elsley, S. (2004) 'Children's experience of public space', Children and Society 18, 2: 155-164.

Florgård, C. and Forsberg, O. (2006) 'Residents' use of remnant natural vegetation in the residential area of Järvafältet, Stockholm', Urban Forestry and Urban Greening 5, 2: 83-92.

Flyvbjerg, B. (2006) 'Five misunderstandings about case-study research', Qualitative Inquiry 12, 2: 219-245.

Francis, M. (1988) 'Negotiating between child and adult design values', Design Studies 9, 2: 67-75.

Gibson, J. J. (1979) The Ecological Approach to Visual Perception. Houghton Mifflin.

Haikkola, L., Pacilli, M. G., Horelli, L. and Prezza, M. (2007) 'Interpretations of urban child-friendliness: A comparative study of two neighborhoods in Helsinki and Rome', Children, Youth and Environments 17, 4: 319-351.

Hill, M. (2006) 'Children's voices on ways of having a voice: Children's and young people's perspectives on methods used in research and consultation', Childhood 13, 1: 69-89.

Horelli, L. (2007) 'Constructing a theoretical framework for environmental child-friendliness', Children, Youth and Environments 17, 4: 267-292.

Janssen, I. and Rosu, A. (2015) 'Undeveloped green space and free-time physical activity in 11 to 13-year-old children', International Journal of Behavioral Nutrition and Physical Activity 12, 1 (online).

Jansson, M. (2015) 'Children's perspectives on playground use as basis for children's participation in local play space management', Local Environment 20, 2: 165-179.

Jansson, M., Mårtensson, F. and Gunnarsson, A. (2018) 'The meaning of participation in school ground greening: a study from project to everyday setting', Landscape Research 43, 1: 163-179.

Jansson, M. and Lindgren, T. (2012) 'A review of the concept "management" in relation to urban landscapes and green spaces: Toward a holistic understanding', Urban Forestry and Urban Greening 11, 2: 139-145.

Jansson, M., Sundevall, E. and Wales, M. (2016), 'The role of green spaces and their management in a child-friendly urban village', Urban Forestry and Urban Greening 18: 228-236.

Kylin, M. (2003) 'Children's dens', Children, Youth and Environments 13, 1: 30-55.

Kylin, M. and Lieberg, M. (2001) 'Barnperspektiv på utemiljön', Nordic Journal of Architectural Research 1: 63-77. 
Kyttä, M. (2004) 'The extent of children's independent mobility and the number of actualized affordances as criteria for child-friendly environments', Journal of Environmental Psychology 24, 2: 179-198.

Lerstrup, I. (2016) Green Settings for Children in Preschools: Affordance-Based Considerations for Design and Management. PhD Thesis, University of Copenhagen.

Lerstrup, I. and Konijnendijk van den Bosch, C. (2017) 'Affordances of outdoor settings for children in preschool: Revisiting Heft's functional taxonomy', Landscape Research 42, 1: 47-62.

Lerstrup, I. and Refshauge, A. D. (2016) 'Characteristics of forest sites used by a Danish forest preschool', Urban Forestry and Urban Greening 20, 387-396.

Loebach, J. and Gilliland, J. (2010)' Child-led tours to uncover children's perceptions and use of neighborhood environments', Children, Youth and Environments 20, 1: 52-90.

Malone, K. and Tranter, P. (2003) 'Children's environmental learning and the use, design and management of schoolgrounds', Children, Youth and Environments 13, 2: 87-137.

Molin, J. F. and van den Bosch, C. C. K. (2014) 'Between big ideas and daily realities: The roles and perspectives of Danish municipal green space managers on public involvement in green space maintenance', Urban Forestry and Urban Greening 13: 553-561.

Moore, R. C. (1986) 'The power of nature: Orientations of girls and boys toward biotic and abiotic play settings on a reconstructed schoolyard', Children's Environments Quarterly 3, 3: 52-69.

Prellwitz, M. and Skär, L. (2007) 'Usability of playgrounds for children with different abilities', Occupational Therapy International 14 3: 144-155.

Randrup, T. B. and Persson, B. (2009) 'Public green spaces in the Nordic countries: Development of a new strategic management regime', Urban Forestry and Urban Greening 8, 1: 31-40.

Rasmussen, K. (2004)' Places for children - children's places', Childhood 11, 2: 155-173.

Riggio, E. (2002) 'Child friendly cities: Good governance in the best interests of the child', Environment and Urbanization 14, 2: 45-58.

Roe, M. (2006) '"Making a wish": Children and the local landscape', Local Environment 11, 2: 163-182.

Simkins, I. and Thwaites, K. (2008) 'Revealing the hidden spatial dimensions of place experience in primary school-age children', Landscape Research 33, 5: 531-546.

Söderström, M., Boldemann, C., Sahlin, U., Mårtensson, F., Raustorp, A. and Blennow, M. (2013) 'The quality of the outdoor environment influences children's health - a cross-sectional study of preschools', Acta Paediatrica 102, 1: 83-91.

Stake, R. E. (1995) The Art of Case Study Research. London: Sage.

Tiller, P.O. (1991) 'Barneperspektivet - om å se og bli sett: Vårt perspektiv på barn - eller omvendt?', Barn - Nyt Fra Forskning om Barn i Norge, 1: 72-77. Trondheim: Norsk senter for barneforskning.

van den Brink, A., Bruns, D., Tobi, H. and Bell, S. (eds) (2016) Research in Landscape Architecture: Methods and Methodology. Abingdon: Routledge. 